Session 2793

\title{
An Interactive Workshop for High School Teachers to Develop and Teach Pre-Engineering Curricula
}

\author{
S. K. Ramesh*, Michael J. Fujita, Preetham Kumar*, Andrew Lindsay, \\ Steven de Haas*, Elizabeth-Gillis Raley \\ *California State University Sacramento / Defense Microelectronics Activity/ \\ Parallax Inc., / Sacramento Engineering and Technology Regional \\ Consortium
}

\begin{abstract}
The College of Engineering and Computer Science at California State University, Sacramento has organized and conducted free interactive workshops for high school teachers who are interested in developing pre-engineering curricula. This year, the workshop was co-sponsored by SETRC (Sacramento Engineering and Technology Regional Consortium) and the Capital Center MESA program (Math, Engineering Science, Achievement). It consisted of "hands-on" laboratory sessions in the morning followed by discussions about curriculum and pedagogy in the afternoon. The high school teachers were divided into teams and rotated through five laboratory stations on Robotics, Digital Circuits, Signal Processing, Optical Engineering, Structures and Materials. Faculty and students from CSUS served as facilitators and worked closely with the teams. The afternoon featured three breakout sessions on the following topics: A: Objectives and Learning Outcomes for an Introduction to Engineering Course, B: Articulating your Introduction to Engineering Course Across the Spectrum, and C: Project based Learning to meet Engineering and Technology Standards.

One of the unique aspects of this workshop was a take-home micro controller kit especially designed by Parallax Inc., for every participating teacher. This module introduces some simple electronic projects (up to 15 different projects) based on the BASIC Stamp 2 single board computer. With the growing popularity of intelligent electronic devices, the BASIC Stamp offers an ideal platform for initial exposure to not only computer programming and electronics, but also to subjects such as robotics, environmental monitoring, and industrial control. Also all teachers received a textbook and a comprehensive workshop manual with additional resources and ideas for lesson plans and curricula. Feedback from the workshop has been very positive. We plan to offer this workshop every year to motivate teachers to develop and offer pre-engineering curricula at the high schools.
\end{abstract}

\section{Introduction}

We are living in a world that is changing rapidly due to dramatic developments in several fields such as communications, energy, transportation, consumer electronics and biotechnology. Technology impacts our daily lives in a profound manner. In order to successfully meet the challenges in the years ahead, it is very important that we encourage young students to pursue careers in science and technology ${ }^{1}$. This is especially critical when one considers the growing gap between the increasing demands in the workforce and the shrinking supply of professionals 
in science, engineering and technology. A recent report by a business organization in the Silicon Valley $^{2}$ indicated that over a third of the 160,000 openings for high technology workers would need to be filled by persons from outside the area. Yet, in Silicon Valley less than $10 \%$ of the 1160 high school students who were surveyed with an expressed interest in high technology careers felt that courses in mathematics, physics, and chemistry were relevant. What can we do to get students interested in science, mathematics and engineering? This issue has been addressed by several educators who have developed curricula to show students how science and technology are relevant to their daily lives ${ }^{3-4}$. Given the magnitude of this challenge all sectors of the educational community and industry need to work together to address the problem effectively ${ }^{5}$. The Sacramento Engineering \& Technology Regional Consortium (SETRC) was formed three years ago to address the need for a comprehensive, collaborative and regional approach to the workforce shortage in Sacramento Valley's Engineering and Technology industries. The Sacramento Engineering and Technology Regional Consortium is an Education and Industry partnership formed to promote engineering and technology career paths to meet industry's need for qualified employees in sufficient numbers. SETRC works with primary schools, middle schools, high schools, and two-year and four-year institutions. There are currently over 60 educational institutions and ten high tech industries actively participating. SETRC, CSUS and the Capitol Center MESA program have collaborated to develop and offer two annual workshops for high school teachers interested in developing and teaching pre-engineering curricula. In this paper we describe the workshops in detail and present feedback from the participants indicating that we are successfully meeting the objectives of the consortium.

\section{SETRC}

SETRC's mission is based on the concept that the development of a technically trained workforce must begin early in the educational pipeline and mechanisms must be in place to support the students and institutions throughout the education process. Students are not receiving the early academic preparation for engineering and technology fields. Awareness and interest in technical careers is exceptionally low.

SETRC's activities include curriculum development and dissemination; developing and strengthening engineering career pathways; improving course sequencing and articulation at the local, regional, and state-wide level; in-service training and workshops for faculty and counselors; development of standards; and work-site training opportunities for students and faculty. SETRC works with regional industry to assess their needs and develop training opportunities for schools, including activities such as mentoring, job shadowing, and tours.

The regional consortium provides a forum where education and industry can voice their concerns, gain feedback, share ideas and reach consensus. Monthly meetings held at rotating sites (schools, industry, CBO's) feature a variety of topics including pre-engineering curriculum, strategies to recruit and retain non-traditional/underrepresented students, and work-site learning experiences for faculty. Industry provides feedback on needed programs and student skills at round table discussions, general meetings and at special committee meetings. Economic Development Programs are partners in training and outreach programs, helping to define needs and implementation strategies.

To help raise interest and awareness, the Consortium sponsors a number of special projects that benefit both students and faculty. Fieldtrips for high school students, faculty and counselors to industry sites, colleges and universities, Engineering Week activities, Career Fairs, Speakers, and 
student contests help recruit and retain students into the engineering and technology field by increasing student awareness. The development of a poster aimed at sparking high school student's interest in engineering and technology fields is underway.

SETRC also sponsors workshops on effective teaching strategies including integrated curriculum, applied learning and integration of standards. The Consortium has been involved with a number of programs that support the development of engineering career pathways at high schools in the region including a workshop that provides teachers the necessary training to implement a Pre-Engineering Course at their respective sites or to integrate the learned skills into an existing course.

\section{CSUS' Role and the 1999 Workshop}

CSUS has been very successful with its 'Introduction to Engineering' course that focuses on fundamental problem solving skills while highlighting the interconnection among the various engineering disciplines ${ }^{6}$. The hands-on nature of the course encourages teamwork, problem solving and critical thinking. The spark of excitement and the discovery-based learning that naturally accompanies the hands on approach is an excellent motivational tool to attract students to study engineering.

Our philosophy is that an introductory course be an introduction to engineering as opposed to an introduction to the discipline of a particular department. It is most valuable for the student to get a feel for how an engineering approach to a particular problem would be different than other approaches. It is helpful to get this in the context of all the different fields of engineering. In some ways this is a very ambitious task as the field of engineering rests on some pretty healthy science and math background, and for more breadth even more background is needed.

Prof. Steven de Haas has developed the ENGR 1 course that he teaches over a number of years looking for key things in the experiments chosen. The key is to find simple experiments that can be almost completely understood by all students. Each experiment needs to be self-contained, not building on more than one previous experiment. The experiments need to cover the broad basics of the major fields of engineering. Experiments should show some current engineering equipment and some should be of a nature to not need any technical equipment.

One of the better experiments in the course is that of dropping rocks off a suspension foot bridge and comparing the distance found by timing the drop compared to a measured distance. They are only given the definitions of velocity and acceleration for analytical tools to work from. This encourages thinking and hopefully moves them away from formula dependency. The best part of this experiment is to ask them to design an experiment to prove their reasons for the error that they are often quick to give in the original experiment. This starts them on the path of some real learning.

Another good experiment is that of having students light a light bulb with computer controlled test equipment, using GPIB and the IEEE 488 interface bus. The experiment is simple - at least at the beginning - and the equipment is impressive. This is actually the first laboratory that electrical engineering students do and often there are some of them in the laboratory doing more advanced experiments. The exchange of information informally is very valuable. 
From this description one will get the correct impression that this introductory course gives the feel for engineering by doing some carefully thought out experiments rather than reading about the professional lives of those in the field. The attempt is to let the student feel the types of problem solving that goes on in the various engineering disciplines, to see if any strike a chord with the student.

Through the Accelerated College Entrance (ACE) program, qualified high school students were able to complete this course along with CSUS freshmen. While this undoubtedly had a very positive impact on the individual students who participated in the program, it was clear that suitable programs needed to be developed in order to reach out to a broader cross-section of students. It was felt that by reaching out to high school teachers we would impact more students interested in the sciences, engineering and technology. This led to the development of the first teachers' workshop that was held at CSUS on October 16, 1999.

The half-day event featured four hands on laboratories in the following areas:

1. Optical Engineering

2. Logic Circuits

3. Civil Engineering

4. Virtual Instrumentation using Lab VIEW

The eight high school teachers who participated in this pilot workshop were divided into four teams and rotated through each of the laboratory stations in 45-minute intervals. Each teacher received a workshop manual with detailed handouts on the labs, resources for lesson plans, and an inexpensive (\$15/kit) take home optical kit to perform experiments. The experiments were designed with high school students in mind and illustrated fundamental concepts from engineering and physics. Each team was led by a CSUS student chaperone who accompanied the team throughout their day and participated in the experiments. Upon completion of the labs, we hosted a luncheon for all the workshop participants followed by a brief discussion and wrap up session.

Examples of hands on laboratories

As an example, we describe the laboratory experiences from the Optical Engineering Laboratory station and the Logic Circuits station. The Optical Engineering laboratory demonstration utilizes the disciplines from statistics, trigonometry, physics, and engineering. Optical Engineering is intriguing in that the energy source used is comprised totally from photons or light energy. In traditional electrical and electronic engineering, analysis and design are performed on systems using electrical currents or electrons.

The primary tool used in these demonstrations is a class 2 , helium neon $(\mathrm{HeNe})$ laser with a fixed wavelength of 632.8 nanometers. This wavelength is preferred for classroom operation due to its visible characteristics. The color seen at this wavelength is 'red'. Clearly, in the research and design environment, scientists opt for the more conventional 1300 or $1550 \mathrm{~nm}$ wavelengths, but these are not visible to the human eye.

As an icebreaker, teachers and students are treated to a tabletop demonstration of what happens to laser light in the classical sense. Mirrors reflect, lenses focus, prisms refract, and multiple slit- 
gratings diffract laser light. All of this may be seen in one setup with the help of a light scattering machine, often called a 'fog machine'.

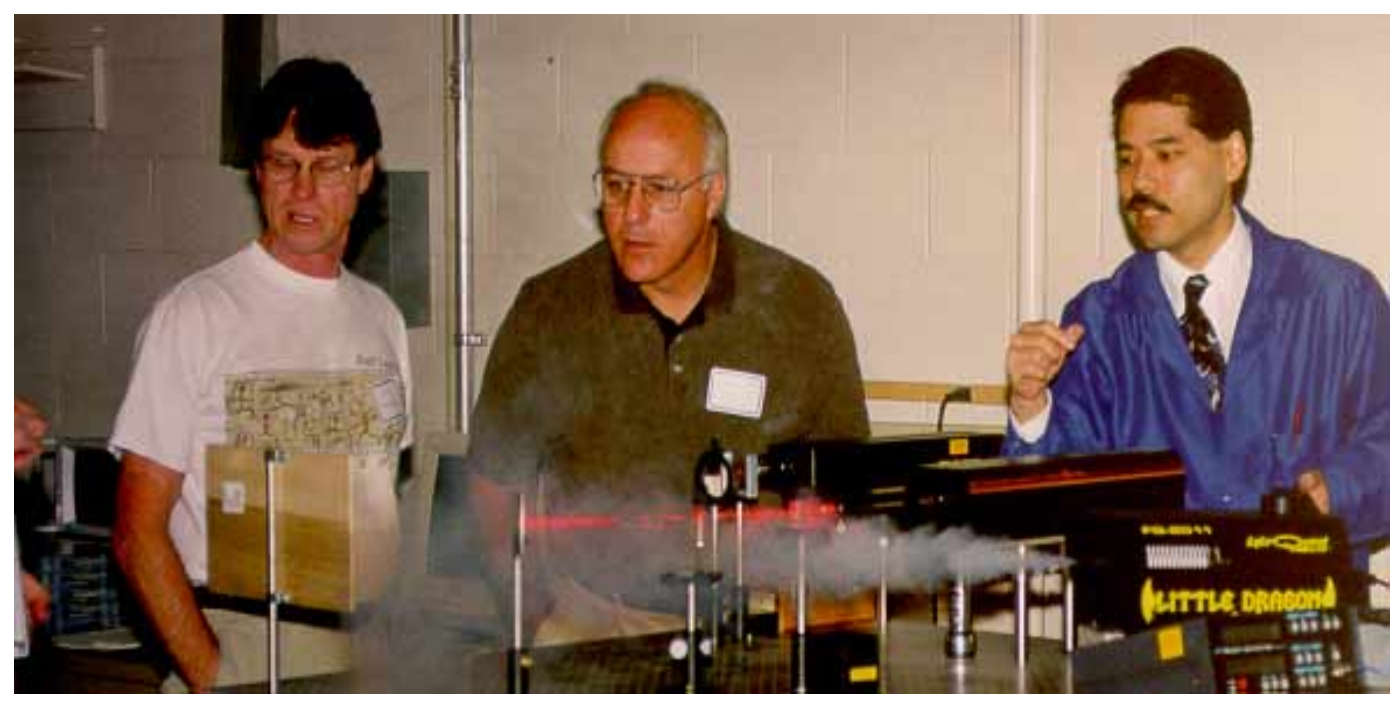

In addition, several other lasers are also used in tandem with the fixed wavelength HeNe laser, notably, a tunable gas laser. The tunable laser may be dynamically tuned to 'red', 'orange', and 'yellow', and observers may see a dynamic demonstration of some of the classical phenomenon of optical engineering. Clearly, this demonstration sets the overall tone for the hands-on experiments that follow.

One of the experiments performed involves the calculation of the wavelength of laser light. This experiment uses a laser, beam expander-collimator, diffraction grating, thin lens, and a board to observe the interference patterns. This experiment has several merits: (1) the observation of light as a wave from the classical nature of light, (2) the understanding of the use of each optical component in the demonstration, (3) the application of trigonometry to engineer the solution, and (4) the validation of the accuracy of the results by comparing them to published data, namely, the $632.8 \mathrm{~nm}$ wavelength. By performing this experiment, teachers and students learn that not only is mathematics an integral part of engineering, but that results are dependent upon the precision of the data taken by the experimenter.

Other experiments performed include the study of Malus' law or polarization of light and determining the attenuation of an optical fiber given two different light sources with different wavelengths. Again, these hands-on experiments require the use of mathematics as well as error analysis. The use of graph papers is required and depending on how accurately the data is taken as well as how well they are recorded and interpreted determines the accuracy of the results. Performing an engineering task requires planning and some well-developed methodology. To reach the goals of an experiment requires many intermediate steps and levels comprised of understanding the goals, development of the procedures, determining what data to record, recording the data, analyzing the data, and verifying the validity of the results.

The Optical Engineering laboratory demonstrations and hands-on experiments enable teachers and students to apply mathematics to an engineering task. At the same time, they are introduced to a different branch of electrical and electronic engineering in the form of optics and lasers called 'optical engineering'. But most importantly, these lab experiments clearly bring out the 
curiosities within the participants and the motivation to continue studying subjects in physics and mathematics that will eventually lead them into the engineering curriculum at the university or college level.

\section{Logic Circuits Session}

An excellent laboratory exercise for an introduction to engineering course is one based on logic circuits. The only preparation by way of background needed is introductory algebra. Boolean algebra is used but for an introductory session what is needed can be taught easily in a short time. Most of the time is spent on wiring the chip and testing to see that the truth table for a simple boolean function is implemented.

The laboratory session begins by identifying each of the chips that have AND gates, or gates and inverter gates using the number on the chip and a schematic from the manufacturer. Each chip is then plugged into a proto board, and a gate on that chip is tested. It is then necessary to power the chip and provide power for testing to the inputs and LEDs for the outputs. These are available as one unit for laboratories for digital circuits.

Starting with the AND gate is a good idea as that probably represents the easiest to understand boolean function. If there is a voltage to each input of the gate the LED on the output will light up. If either input voltage goes off the LED will turn off, indicating one input and the other must be on for the gate to turn on. The OR and the inverter gates are tested in the same way. The emphasis is on playing with the chips at this level until the individual really feels confident with the ideas and implementation.

Then gates are then combined together to implement a boolean function like (A AND B, or A AND B complement). The circuit is drawn and the truth table is written for the function. From the drawn circuit, the circuit is wired on the proto board and then tested to see if it follows the truth table. It is actually better when it doesn't initially work as this illustrates good engineering techniques needed to more easily find the problem.

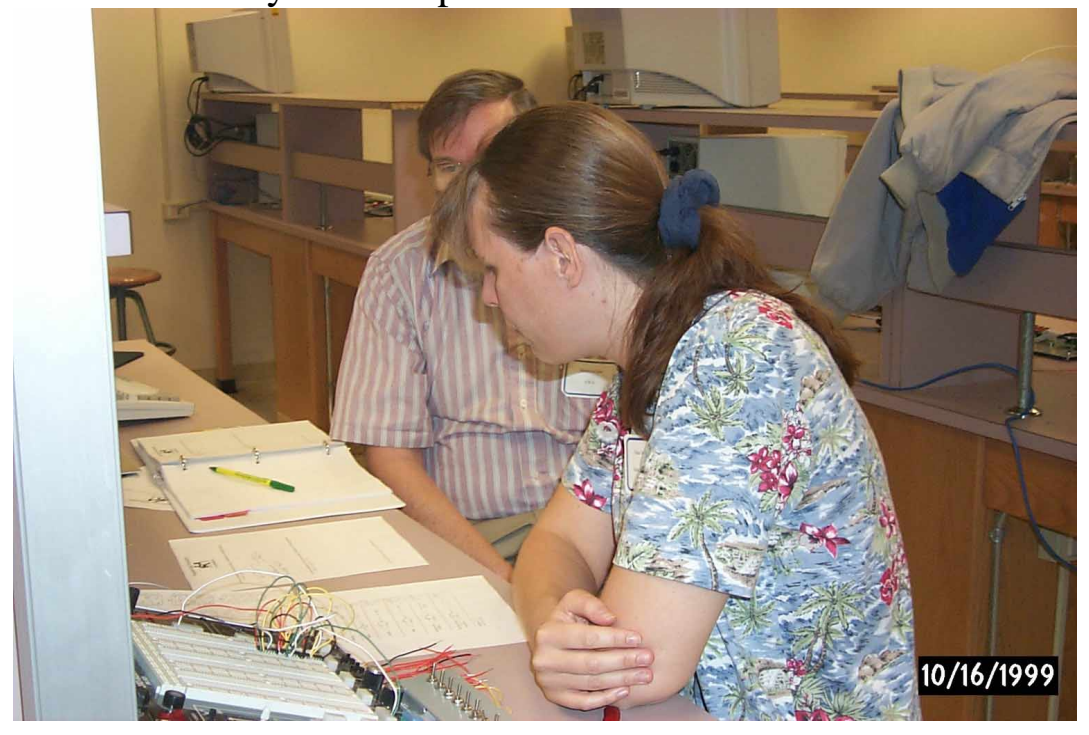

From here different boolean functions are given to show different possibilities and to increase the difficulty. More difficult functions will almost ensure a circuit not working properly which gives the possibility of learning de-bugging techniques. More complex circuits also begin to show how 
useful these circuits might be. To help foster creativity and get some individuals a little more interested, It is suggested that they devise a function of their own to implement. This usually brings on a whole new set of problems to solve. This is an excellent experiment as it gets individuals quickly into real engineering type work without a lot of theoretical preparation. It is a fun laboratory.

Following the 1999 workshop, the evaluation forms were gathered and analyzed to see how well the goals of the workshop were being met. Participants ranked several attributes of the programs on a scale of 1 (Poor) to 5 (Excellent). These are summarized in Table I below:

The number of respondents under each category is summarized in this table.

\begin{tabular}{|l|l|l|l|l|l|}
\hline Rating of attributes & $\begin{array}{l}\text { Poor } \\
1\end{array}$ & 2 & 3 & 4 & $\begin{array}{l}\text { Excellent } \\
\end{array}$ \\
\hline Quality of Presentation & & & & 1 & 7 \\
\hline Value of Information & & & 1 & 2 & 5 \\
\hline Length of Presentation & & & 3 & 2 & 3 \\
\hline Quality of Literature & & & 1 & 1 & 6 \\
\hline "Hands on" Labs & & & & 2 & 6 \\
\hline Lab Facilitators & & & & & 8 \\
\hline
\end{tabular}

Table I: 1999 Workshop Attribute ratings by respondents

The feedback was overwhelmingly positive from the participants. It was evident that they really appreciated the interaction with the faculty, students and other teachers from area high schools. Also several constructive comments were made which we later incorporated in the sequel during our October 2000 workshop last year. These are summarized below:

1. Participants requested additional time following the labs for reflection and discussion on course development, pedagogy, articulation and standards.

2. Some experiments could not be completed within the 45-minute interval. Additional time is needed to complete the experiment. The Lab VIEW experiment was rated the most complex and it was recommended that we either modify it to make it more relevant for a high school audience or drop it all together.

IV. The October 2000 Workshop

The goals of the October 2000 workshop were:

- Assist high school teachers to develop and offer introductory engineering courses at their home campuses

-Establish a collaborative community of engineering educators at all levels through the SETRC to share and exchange information and ideas to improve engineering/technology education

Based on the feedback from the teams in October 1999, we made a few changes to the format of the workshop. These are summarized below: 
1. First, we added three breakout sessions in the afternoon to address issues ranging from course development and articulation, to statewide content standards and project based learning to meet standards. These sessions were scheduled for the post-lunch period and were followed by a plenary where the session leaders presented summaries from each breakout session.

2. The laboratory experiments were carefully redesigned so that they would be more relevant to high school students. We introduced a new experiment illustrating the application of microcontrollers and robotics with a custom designed kit from Parallax, Inc., This is described in detail in the next section. With funding from the workshop we provided each teacher with a take home microcontroller kit valued at $\$ 100 / \mathrm{kit}$, with which they could perform up to 15 experiments. We decided to drop the experiment on Lab VIEW and introduced a simpler experiment utilizing MATLAB/Simulink instead. This experiment demonstrated concepts from communication engineering and is also described in the next section. The structures experiment in the civil engineering $\operatorname{area}^{7}$ was also modified from the first version that was offered in 1999. This is described in detail in another paper at this conference ${ }^{7}$.

3. We increased the time spent/station from 45 minutes to 60 minutes and accommodated the additional labs by starting earlier in the day. The workshop began at 7:30 AM and concluded by 5:30 PM.

4. In addition to the workshop manual and kit, every teacher received a complimentary copy of "Engineering your Future", a textbook ${ }^{8}$ suitable for an Introductory Engineering Course.

The five laboratory stations set up for the workshop were:

STATION 1: OPTICAL ENGINEERING LAB(Santa Clara Hall 1108)

STATION 2: STRUCTURES LAB (Riverside Hall 1001)

STATION 3: DIGITAL CIRCUITS LAB (Riverside Hall 3005)

STATION 4: EXPERIMENTS USING THE PARALLAX KIT (Riverside Hall 3017)

STATION 5: SIGNAL PROCESSING LAB (Riverside Hall 5017)

\section{The New laboratory experiments in the 2000 Workshop}

\section{(a) SETRC Introduction to Microcontrollers Workshop}

First we examine the rationale for earlier student exposure to embedded systems applications. Embedded processors, also referred to in this article as embedded systems, are well on their way to becoming ubiquitous in electronic and electromechanical systems. Just a few of the places embedded processors can be found are kitchen appliances, automobile subsystems, handheld products, and automated machinery. As embedded processors become smaller, easier to use, and more versatile, their popularity in product and equipment designs is sure to continue to grow. The impact of this design trend is most marked in the fields of electrical and mechanical engineering, and of course, in the fledgling field of mechatronics. The products and equipment designed by engineering teams in these fields tend to feature embedded processors, computer control inputs/outputs, or both.

The trends just cited beg the examination of two issues in engineering education. First, embedded systems in electronics are often not introduced until students reach senior level engineering courses. This late introduction can often become a stumbling block in student 
designs. Earlier exposure to this topic could make the transition from theory to this application easier. Second, system integration of microcontrolled electronic input into mechanical systems is also often not introduced until senior level. Although mechatronics typically pushes both types of system integration to junior level courses, the mental hurdle of synthesizing fundamental principals in computer programming, electricity and electronics, and mechanics into a single design can be a formidable obstacle for many students.

The time line for exposing students to microcontrolled electronics, mechanics, and system integration in engineering school is understandably compressed. Engineering program requirements typically increase instead of decrease. High school level preparatory programs such as engineering academies and pre-engineering preparatory classes tend to recognize the need for earlier exposure to engineering concepts, and they also tend to place an emphasis on the fundamentals. A second and almost equally important service that such programs can provide for their students is hands-on, simplified exposure to some of the more elusive and abstract engineering concepts. It stands to reason that students who receive early, simplified exposure to topics in a given field can be expected to perform better than a student with no prior experience in said field. Microcontrolled electronics and mechatronics are two such areas where this type of early, simplified hands-on exposure could be highly beneficial.

\section{Microcontroller Introduction Kit and Documentation}

Parallax, Inc., a Rocklin, California based developer and manufacturer of single board computers and microcontroller programming tools, recognized this demand for early exposure to embedded systems design. In response to this demand, Parallax, Inc. began the Stamps in Class ${ }^{\mathrm{TM}}$ curricula, which is now in its fourth year of development. The Stamps In Class curricula ${ }^{9}$ uses the Parallax BASIC Stamp single board computer, often loosely referred to as a microcontroller, as the embedded processor basis for exposure to introductory program controlled electronics, mechatronics, industrial control, and sensor interface.

The BASIC Stamp is so named because it is a postage stamp size computer that is programmed in PBASIC, a subset of the BASIC computer programming language that also features commands designed to support embedded processor fundamentals such as communication with external peripherals, analog, and digital I/O. The BASIC Stamp is used extensively in industry as an embedded system, both for rapid prototyping and in end products. It also has a variety of features that make it attractive to educational institutions. Most notably, the startup cost to for educational institutions that use this product is relatively low. Cost varies depending on the application, but the typical cost ranges between $\$ 120$ and \$250 US per computer. The low cost combined with the BASIC Stamp's intuitively simple programming language and easy to use software make it possible for instructors to provide hands-on introductions to otherwise advanced study engineering topics such as: analog to digital and digital to analog conversion, microcontroller sensor interfaces, microcontrolled mechatronics (robotics), and industrial control. Parallax also provides texts available for free download ${ }^{9}$ at www.stampsinclass.com that document and support experiments in these areas. Freeware and documentation for programming the BASIC Stamp is available from www.parallaxinc.com.

The Microcontroller Introduction kit contains everything an instructor needs to try 15 different experiments. The core of the kit is the BASIC Stamp 2 single board computer and the Board of Education, a carrier board and prototyping environment designed for the BASIC Stamp 2 and Stamps in Class curriculum. The kit also includes a serial cable, Parallax CD, and Basic Analog 
and Digital parts kit. The serial cable is used to connect the Board of Education to a PC's serial port for downloading programs to the BASIC Stamp 2. The Parallax CD contains the BASIC Stamp Windows Interface, v1.096, which is used to develop PBASIC programs, download them to the BASIC Stamp 2, and display messages from the BASIC Stamp 2. Also included on the CD are the BASIC Stamp Manual v1.9, and all texts in the Stamps in Class series. All these resources are also available at the Parallax web sites mentioned earlier.

The Microcontroller Introduction kit also contained the Basic Analog and Digital parts kit. The parts in this kit can be used for all experiments in the Basic Analog and Digital ${ }^{10}$ text as well as in four experiments in What's a Microcontroller and activities in three experiments in Industrial Control $^{11}$. This allows instructors the broad range of further experimentation after the workshop.

The SETRC Microcontroller Introduction Instructor's Guide is written to accompany the SETRC Microcontroller Introduction kit, and it was incorporated into SETRC workshop manual. This document contains a general introduction to microcontrolled electronics, getting started instructions for the BASIC Stamp, resources suggestions pertaining to the Parallax CD, and an excerpt of Experiment 1 from the introductory What's a Microcontroller text.

\section{Microcontroller Introduction Lab}

The SETRC Microcontroller Introduction module was one of five hands-on labs where high school instructors were exposed to both fundamental and sometimes more advanced engineering topics. In this module the concept of embedded processors was first introduced by example through a variety of robotics demonstrations. These robotics demonstrations were chosen because the sensor inputs and mechanical outputs are more visible, tangible, and easy to discuss in layperson's terms. As an ice breaker, a walking robot developed by Parallax, Inc. called the Toddler takes a walk up to various instructors, beeps a "Hello" recognition, then turns and walks away in search of other instructors to greet. Its comical gait and slow response times tend to elicit discussion of improved performance.

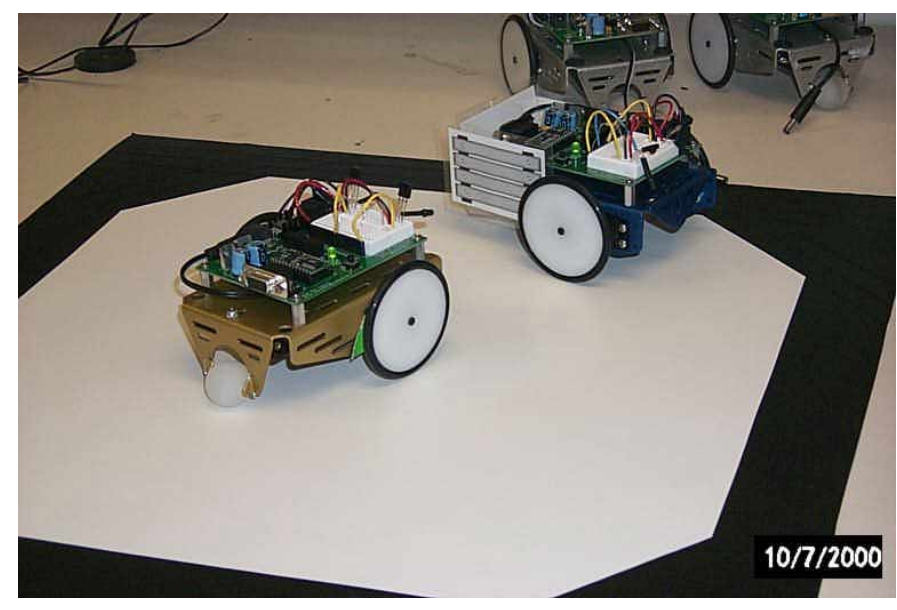

This performance discussion leads naturally to the engineering topic of sampling and sampling rates. Two robots featured in Chapter 6 of Parallax' Robotics! $!^{12}$ text are then demonstrated. The lead robot, called a Board of Education Robot (Boe-Bot), roams autonomously on a white surface delimited by black electrical tape. The lead Boe-Bot's BASIC Stamp 2 embedded processor is programmed in PBASIC to detect and turn away from the black electrical tape. The second Boe-Bot is programmed to detect and follow the first Boe-Bot as it roams. This 
experiment is the sixth in the Parallax Robotics! ${ }^{12}$ Text and it features introductions to the concepts of feedback, proportional control, and frequency response. The emphasis in discussing this demonstration rests on a brief discussion of sampling rate and laypersons' introductions to feedback, control, and sensors, all of which are evident in the demonstration.

This discussion is followed by a general discussion of embedded processors and their role in engineering. A commercial product, the Owl (data logging) weather station designed by EME Systems is displayed and operated as an example of an embedded application. A CSUS student project, the Occulo-Mouse, a mouse directed by eye movement, is provided as a second example of a complex system with an embedded design. Next, three demonstrations from the Stamps in Class series, Experiments 1 and 3 from Basic Analog and Digital, Experiments 1 and 2 from Earth Measurements and Experiment 4 from Industrial Control are displayed and briefly discussed. These completed experiments are demonstrated and explained for two reasons. First, they provide examples of components within the more complex systems demonstrated earlier. Second, they provide a survey of embedded processor experiments. The Robotics!, Industrial Control, and Earth Measurements demonstrations provide an overview of the wide variety of areas where embedded control experiments can be done in an educational setting. The Basic Analog and Digital experiments add to this list of examples, but they also provide examples of two experiments that every instructor who participates in the workshop can try at his or her convenience after the workshop because the Basic Analog and Digital parts kit is included in the SETRC Microcontroller Introduction kit. Following the introduction of the Stamps in Class Experiments, the instructors are directed to examine the contents of their SETRC Introduction to Microcontrollers kit.

The lab facilitator next guides the instructors through the "getting started" portion of the SETRC Microcontroller Introduction Instructor's Manual included in the SETRC Workshop Manual. The Microcontroller Introduction Instructors Manual has instructions for connecting power and serial cable to the BASIC Stamp 2 and Board of Education and running and testing a sample PBASIC program with the BASIC Stamp 2. This activity not only provides the facilitator an opportunity to guide the instructors through initial assembly and testing, it also enables the facilitator to show the teachers where to find the programming software, documentation, and educational texts on the Parallax CD. Next, the facilitator guides the high school teachers through Experiment 1 in the What's a Microcontroller text. This experiment involves connecting an LED circuit to the BASIC Stamp 2 and writing a program to make the LED turn on and off. This activity demonstrates how a programmable embedded processor can be used to control a circuit. All instructors successfully completed these first two activities.

The concept of embedded processor circuit control was next extended to embedded processor circuit data acquisition. In other words, the concept of sending an output was extended to listening to an input. The input in question is the pushbutton circuit featured in Experiment 2 in the What's a Microcontroller text, which is not included in the SETRC Microcontroller Introduction manual since the entire text is included on the Parallax CD. The circuit and activity are briefly discussed and recommended as a next step in exploring microcontrolled circuits with the SETRC Microcontroller Introduction kit. As a wrap-up activity, the instructors are shown a second time where to find the software and documentation resources to complete the remaining fourteen of fifteen experiments discussed earlier.

(b) The Digital Signal Processing Laboratory 
The Digital Signal Processing (DSP) laboratory station in the October 2000 workshop replaced the Lab VIEW experiment from 1999 and focuses on the analysis, simulation and measurement of analog/digital signals and systems. The experiments for the high school teachers were divided into 3 sections: one signal measurement experiment, and two signal/system simulation

experiments. The first experiment involved the measurement of simple periodic signals, such as sine, square and triangular signals in time (using the oscilloscope), and in frequency (using the spectrum analyzer). The second experiment simulated the results of experiment 1 using the SIMULINK software, and results were compared. The main motivation behind experiments 1 and 2 is to demonstrate time and frequency characteristics of signals, and Fourier splitting of a periodic signal into its harmonic components. The third experiment involved the SIMULINK simulation of a fundamental low pass filter circuit having a cutoff frequency of $10 \mathrm{rad} . / \mathrm{s}$. Input sinusoidal signals were varied in frequency from $0 \mathrm{rad} . / \mathrm{s}-50 \mathrm{rad} . / \mathrm{s}$, and the performance of the low pass filter was recorded. The motivation behind this experiment is to demonstrate working of filters, which are important in all communication circuits.

\section{(c) Summary of Breakout Sessions}

\section{Session A:}

This breakout session led by Prof. Steven de Haas, on planning an Introduction to Engineering Course ended up talking mostly about concepts in teaching. The following major concepts were suggested and discussed:

1. We need to think of students as possessing all the skills and abilities needed for doing the task at hand and that we are there to help them begin using them.

2. Ownership is key in the learning environment.

3. There is less difference in the capabilities of individuals than we make believe by the grades we assign. Most of these differences are due to things that inhibit learning like emotional circumstances.

One of the concerns raised during the discussion was how to get students away from formulas either copied or memorized and into real thinking. It was agreed that this was a problem and often came from the drive to learn more and to try to learn it more quickly. Teachers said that this pressure came from both parents and administration.

One person came with a question of how computers could be effectively used in an Introduction to Engineering Course. There were some simple suggestions for presenting material and some very simple diagnostic kinds of experiments. More than one person said that it was important to see that the student could do things without the computer before progressing to the tasks that used it. From experiments in college classes in engineering, too many times students have confused simulation with data from a real experiment.

Some were concerned about the push for assessment and its eventual effect on real learning. While we all seemed to have an idea of what each of us thought real learning was, we realized that it would be a significant task to get that described. We started by agreeing that it meant an ownership of the concepts being learned. That ownership could be displayed by describing the concepts and especially if that could be done in a new context. The group felt that learning communication skills should be a key element in an Introduction to Engineering class. 
Most at this discussion group seemed to feel that just coming together to share ideas and look at concepts that could make for a better course was well worth the time. Many felt the breakout session was too brief. We will consider devoting more time to such sessions during next year's workshop.

\title{
Session B
}

This session led by Prof. S. K. Ramesh, dealt with articulation issues between high schools, community colleges and universities in the context of an Introductory Engineering Course. CSUS has established such agreements with local high schools such as Cordova High School, Sheldon High School and Valley High School. These programs are generally handled through the Accelerated College Entrance Program (ACE) Program. Courses covered under these agreements include ENGR 1 (Introduction to Engineering), and ENGR 6 \& 7 (Introduction to AutoCAD and drafting). Participants had an opportunity to discuss the issues surrounding articulation and the nuts and bolts of bringing it to fruition. Examples of ACE programs between CSUS and Area High Schools fall under one of these categories: (1) Individual students take classes at CSUS, (2) CSUS instructors provide instruction on site at the high school or via distance learning, and (3) CSUS instructors work together with high school teachers and team teach a course.

\section{Session C}

Dr. Scott Griffith, Dean of the Engineering and Technology Center housed at American River College, led this session focusing on project based learning to meet state content standards. Math and Science Standards for the State of California may be found at http://www.cde.ca.gov/board/. The final approved set of standards for engineering and technology may be found at http://ic.arc.losrios.cc.ca.us/ engintp/forum/messages/21.html

\section{Summary of feedback from the 2000 Workshop}

Financial support for the workshop came from CSUS, SETRC and the Capital Center MESA program. A dozen faculty members and over twenty CSUS students were actively involved in conducting all facets of the workshop. Their contributions were recognized with an honorarium and a certificate.

Table II provides a summary of the ratings from the 2000 workshop. E-mail Comments from participants following the workshop are listed at the end of the paper.

Fourteen teachers attended the workshop. The teachers were from the following schools:

\author{
Center High School \\ Oakmont High School \\ Milpitas High School \\ Roseville High School \\ Colfax High School \\ Casa Robles High School \\ Marina Middle School \\ Grant West \\ Cameroun Society of Engineers/CA Middle School
}


Each participant was requested to complete a feedback form with five questions. Responses from the questions are summarized below.

1. Did the workshop meet your expectations?

Yes -8, No -1

The person who responded "No" had the following comment: "It far far exceeded them Awesome"!

One person who responded "Yes" had the following comment: "In Most Part"

2. Please rate the following attributes of today's event on a 5-point scale, where 1 means "poor" and 5 means "excellent".

Under Quality of Presentation two persons rated the program at 6 on a scale of 5.

Under "Hands on Labs" one person rated the program at 6 on a scale of 5.

Under Lab Facilitators one person rated the program at 6 on a scale of 5.

Under Quality of Literature two persons responded that they couldn't comment, as they were yet to review the material.

The number of respondents under each category is summarized in this table.

\begin{tabular}{|l|l|l|l|l|l|}
\hline Rating of attributes & $\begin{array}{l}\text { Poor } \\
1\end{array}$ & 2 & 3 & 4 & $\begin{array}{l}\text { Excellent } \\
\text { Quality of Presentation }\end{array}$ \\
\hline Value of Information & & & & 1 & 6 \\
\hline Length of Presentation & & & 1 & 1 & 6 \\
\hline Quality of Literature & & & & 1 & 6 \\
\hline "Hands on" Labs & & & & 1 & 7 \\
\hline Lab Facilitators & & & & 1 & 7 \\
\hline
\end{tabular}

3. What did you like best about the workshop?

- The hands on and material and ideas for projects

○ The Variety of Labs

- Labs, the one to one attention is a must because the labs are over most people's heads. I liked the strict timeline (time at each lab was just about right). Transition was smooth. I liked having a personal guide with us all the time. I liked things all being in the same building. I liked the raffle even though I didn't win.

○ Providing Materials for Robotics and Digital Circuits

- To learn activities available for students

○ Hands on labs

- Hands on

○ Expanded understanding of and connections of CSUS Engineering 
4. What did you like least about the workshop?

○ Presentation Only ( some, not all)

- A few labs seemed too complicated for someone with no background

o Finding Riverside Hall !!! Not enough Diet Drinks !!! Some of the English with accent hard to understand

○ The length of the day

○ Robot/microprocessor section much too short to get adequate info.

- Afternoon breakout sessions/not much time for interaction

○ Too little time to experiment

○ Signal Processing: Needed a different introduction. I needed to understand how this related to industry. Then how I could relate it to my high school students.

\section{Questions/Comments}

"The best presentations were the ones with written modules and follow up with hands on directions. To allow us to try. One-on-One really good."

"I really valued the personal attention and would recommend it! The hands-on labs were very organized and almost all were at a level that could be used for high school. The only lab I would rethink would be the wavelength lab. The software is affordable for it but seems complicated."

"This was a wonderful workshop. I will make this a mandatory workshop for my people. All the hosts were very kind and patient. Very good exposure to engineering. Very good discussions about the art and science of teaching engineering or anything for that matter."

"I really appreciate the focus on project based learning. The Parallax microcomputer onboard with CD and text is an excellent curriculum to teach digital circuits, robotics and electronics. This was the best workshop I have seen in years for technology education."

"Too many short hands-on workshops are not as useful as fewer more in depth workshops. More emphasis on secondary classroom friendly labs. What we did (lab) today might make a good field trip for students (high school).

Establish "pre-approved" "Continuing education" credit with area districts, and advertise through districts (catalogs of staff development activities). Most districts have few science/math offerings.

Too many activities for one day! Either pare it down or meet on more than one date!

Inform people about luncheon (if provided). Send map w/enrollment materials.

MESA is co-sponsoring-but we did not learn about what MESA is doing these days. I remember it as minority only. Is this still true?

Offer a week long summer workshop to help teachers plan/practice a pre-engineering course curriculum (text, labs, sources etc.,)." 
"Need to mail out directions to workshop: Will help.

Speakers at end of lab activities were great, especially information on ways to teach that have been successful in some universities."

"1. Make continuing education units available.

2. Provide a session where teachers can discuss and share what we are currently doing in our classes. Share project ideas.

3. Use classrooms with tables.

4. Would prefer next session in August, rather than June.

5. Food was great. Lots of useful information and materials provided."

"Great workshop overall. The chance to have my kids (students) work on real engineering stuff (breadboards, IC's, computer interface) is just too much of a chance to pass up. Kids need to experience the activities of the workshop so they get an immediate engineering feel."

"Always a challenge- when you have everyone rotate from session to session where an individual wants to spend more time at one station and less time at another."

A sampling of the comments received after the workshop by e-mail are listed below (edited for space)

"Thank you for such a useful and well-organized event. I've been doing a multitude of conferences ever since I starting working with MESA. This was the best I've seen in years!

The robotic workshop form Parallax answered several of my concerns for teaching Introduction to Engineering at Center. Here is a low-cost curriculum that allows students to:

read schematics, design and build circuits, learn digital devices, learn programming language, and build a project robot. (Most of the students that signed up for my course were expecting something like this.) I've been playing with it for hours! THANK YOU!"

My only disappointment is that more Sacramento area teachers did not take advantage of this event.

\section{Jim Fritch}

\section{Center High School}

"It was very exciting to take part in the MESA program that you hosted at SSU. It was a full day well spent! Kudos to you and all those who put the great program together. I am loaded with a lot of new ideas...Does learning ever cease?

I attended as a Science teacher with a lot of passion to motivate students in becoming practical scientist and also as the Secretary of the Cameroonian Society of Engineers- USA Chapter which is a non profit organization. One of our goals is to tutor K12 students and motivate them in sciences."

..." It is a workshop all science teachers should attend."

\section{Comfort Ateh Ph.D}

Secretary, CSE-USA Chapter

"Thank you for the great day on Saturday, it took me another day to go over all the material. The workshops were fantastic and I would love to teach an Introduction to Engineering class. I 
don't know how receptive the administration would be to the class, but it seems a natural application of Pre-Calculus and Physics.

I currently teach Geometry and Pre-Calculus and do a lot of AutoCad drafting in my Geometry classes, another good link to an Engineering curriculum."

\section{Jonathan Schwartz Colfax High School}

\section{Conclusions}

The feedback from the participants indicates that several teachers have already begun to use the material from the workshop in their curriculum and some are actively planning to integrate it into courses they teach. The one on one interaction with faculty, students and other teachers emerged as the most positive outcome from the workshop. The workshops have been very well received by the high school teachers in our area. With SETRC, MESA and industry providing support and CSUS providing a foundation, we now have a collaborative community of teachers, and students spanning the spectrum from K-12 through the University. We believe that this will lead to new ideas and novel teaching innovations to motivate students to study science, engineering and technology. We intend to follow up with all the workshop participants over the past two years and survey them about their specific experiences in integrating material from the workshop into their curricula. Also a list serve has been established under the auspices of SETRC so that all workshop participants can collaborate online. Some of the comments from the most recent workshop indicated that the participants would prefer a longer format (two days) rather than a daylong workshop. Other suggestions included offering CEU credit for teachers participating in the workshop. We will seriously examine these and other suggestions as we look forward to the next edition of the workshop that is tentatively scheduled for October 2001.

Bibliography

1. "Engineering Education for a Changing World", ASEE project report, ASEE Prism, Pages 20-27, December 1994.

2. URL : www.jointventure.org/initiatives/edt/work_gap/student.html

3. Deran Hanesian, Angelo J. Perna, "Introducing $6^{\text {th }}$ to $12^{\text {th }}$ grade students in K to 12 Programs to Science and Engineering through Experimental Measurements", Proceedings of the $29^{\text {th }}$ ASEE/IEEE Frontiers in Education Conference, Paper 1468, Session 12d-4, San Juan, Puerto Rico, November 1999.

4. Mike Robinson, M. Sami Fadali, J. Carr, C. Maddux, "Engineering Principles for High School Students," Proceedings of the $29^{\text {th }}$ ASEE/IEEE Frontiers in Education Conference, Paper 1096, Session 13a-7, San Juan, Puerto Rico, November 1999.

5. Mary R. Anderson Rowland, Maria Reyes, Cathryne Jordan, and Mary Ann McCartney, " A Model for Academia, Industry, and Government collaboration for K-12 Outreach," Proceedings of the 29 ${ }^{\text {th }}$ ASEE/IEEE Frontiers in Education Conference, Paper 1420, Session 13a7-2, San Juan, Puerto Rico, November 1999.

6. S. K. Ramesh, "Introduction to Engineering: Attract Students and Strengthen the Pipeline," Proceedings of the $29^{\text {th }}$ ASEE/IEEE Frontiers in Education Conference, Paper 1398, Session 13d7-1, San Juan, Puerto Rico, November 1999.

7. Eric Matsumoto, John Johnston, Ed Dammel, and S. K. Ramesh, “A Simple Beam test : Motivating High School Teachers to develop Pre-Engineering Curricula," Under Review, 2001 ASEE Annual Conference \& Exposition.

8. Oakes, Leone and Gunn, “Engineering your Future," Great Lakes Press, First Edition, 1999.

9. URL: www.stampsinclass.com

10. “Basic Analog and Digital” Version 1.0, Parallax Inc., 1999.

11. "Industrial Control" Student Workbook, Version 1.0, Parallax Inc., 1999.

12. "Robotics!" Student Guide, Version 1.3, Parallax Inc., 2000. 


\section{S. K. RAMESH}

Dr. S. K. Ramesh is a Professor of Electrical and Electronic Engineering at California State University, Sacramento and has been the Department Chair since 1994. His research interests are in the area of Optical Communication Systems. He teaches courses in Optical Engineering, Fiber Optic Communications and Analog IC Design. He is a Senior Member of the IEEE and is presently the Central Area Chair of IEEE Region 6. Dr. Ramesh graduated with a B.E. (Honors) degree ('81) in Electronics and Communication Engineering from the University of Madras, India, and received his MSEE ('83) and $\mathrm{PhD}$ ('86) degrees from Southern Illinois University, Carbondale.

\section{MICHAEL J. FUJITA}

Michael Fujita is currently a lecturer at the California State University at Sacramento. He received his B.S. and M.S. in Electrical and Electronic Engineering from CSUS. His teaching interests include optical engineering and circuit analysis. In addition to teaching, Michael works as a microelectronics design engineer at the Defense Microelectronics Activity, Office of the Secretary of Defense in Sacramento, California.

\section{PREETHAM B. KUMAR}

Dr. Preetham B. Kumar received his Ph.D in Electrical Engineering from the Indian Institute of Technology, Madras in 1993. He has worked as researcher/lecturer in the RF \& Microwave Laboratory, University of California, Davis, and also as a part-time faculty member in the Department of Electrical and Electronic Engineering, California State University, Sacramento (CSUS). He joined CSUS on a full-time basis in August 1999, and teaches courses in DSP, Microwave Engineering and Wireless Communications. He has published more than 35 papers in journals and international conferences in the areas of antenna design, RF and microwave circuits.

\section{ANDREW LINDSAY}

Andrew Lindsay, BSEEE, studied at California State University, Sacramento, and graduated with Honors. At the time of this writing, he does curriculum development, applications engineering, and technical writing for Parallax, Inc. Andrew is primary author of the BASIC Analog and Digital text and the Robotics! Text, v1.3 and up. Both texts are published by Parallax, Inc. Andrew frequently travels to present BASIC Stamp Educators Workshops. These workshops show educators how to use the BASIC Stamp 2 in a variety of experiments ranging in complexity from those for use in high schools to those designed for use in technical and engineering schools. Andrew is a member of CCEI, the California Council of Electronics Instructors.

\section{STEVEN de HAAS}

Dr. Steven de Haas is a Professor of Electrical and Electronic Engineering at California State University, Sacramento, where he has taught for over fifteen years. He teaches courses on circuits, and control systems and has developed and taught the "Introduction to Engineering" course at CSUS. Dr. de Haas received his PhD degree from the University of California, at Davis.

\section{ELIZABETH GILLIS-RALEY}

Elizabeth Gillis Raley, P. E., is a registered Civil Engineer with over 20 years of engineering, management and education program development experience. As Director of the Sacramento Engineering \& Technology Regional Consortium, Ms. Raley is responsible for leading a progressive, proactive collaboration of education and industry partners to improve engineering and technology education programs. Ms. Raley received her B.S. in Civil Engineering from the Georgia Institute of Technology in 1979 and her M.S. in Civil Engineering from California State University, Sacramento in 1987. 